\title{
Synthesis of phosphoramidites of isoGNA, an isomer of glycerol nucleic acid
}

\author{
Keunsoo Kim, Venkateshwarlu Punna, Phaneendrasai Karri \\ and Ramanarayanan Krishnamurthy*
}

\author{
Full Research Paper \\ Address: \\ Department of Chemistry, The Scripps Research Institute, 10550 \\ North Torrey Pines Rd, La Jolla, CA 92037, USA \\ Email: \\ Ramanarayanan Krishnamurthy * rkrishna@scripps.edu \\ * Corresponding author \\ Keywords: \\ acyclic nucleic acids; glycerol nucleic acids; isoGNA; oligonucleotides; \\ phosphoramidites \\ Beilstein J. Org. Chem. 2014, 10, 2131-2138. \\ doi: $10.3762 /$ bjoc. 10.220 \\ Received: 01 May 2014 \\ Accepted: 15 August 2014 \\ Published: 08 September 2014 \\ This article is part of the Thematic Series "Nucleic acid chemistry". \\ Guest Editor: H.-A. Wagenknecht \\ (c) 2014 Kim et al; licensee Beilstein-Institut. \\ License and terms: see end of document.
}

Open Access

\begin{abstract}
IsoGNA, an isomer of glycerol nucleic acid GNA, is a flexible (acyclic) nucleic acid with bases directly attached to its linear backbone. IsoGNA exhibits (limited) base-pairing properties which are unique compared to other known flexible nucleic acids. Herein, we report on the details of the preparation of isoGNA phosphoramidites and an alternative route for the synthesis of the adenine derivative. The synthetic improvements described here enable an easy access to isoGNA and allows for the further exploration of this structural unit in oligonucleotide chemistry thereby spurring investigations of its usefulness and applicability.
\end{abstract}

\section{Introduction}

Acyclic nucleic acids have garnered a lot of attention and are becoming an important component in nucleic acid chemistry [1-3]. Lately, there has been an explosion in the number of investigated candidates [4-7]. We have recently reported on the base-pairing properties of isoGNA, an isomer of glycerol derived nucleic acid (Figure 1) [8]. Our motivation was driven by the question "how structurally simple and minimal can an oligonucleotide be and still exhibit base-pairing?" When we studied isoGNA we were surprised to find that the base-pairing properties were unpredictably different from other closely related acyclic nucleic acids [8]. This indicated that the nature of the backbone exerts a strong influence on the disposition of the nucleobases, and there seems to be no straightforward correlation between the nature of the backbone and base-pairing properties [9].

We are continuing our investigation of isoGNA oligonucleotides within the context of chimeric sequences and collaborative intercalation studies and thus have a continuing need for the synthesis of isoGNA building blocks. While iso-glycerol nucleosides are known [10-15], the published synthetic routes and efficiencies of these vary widely and primarily depend on 

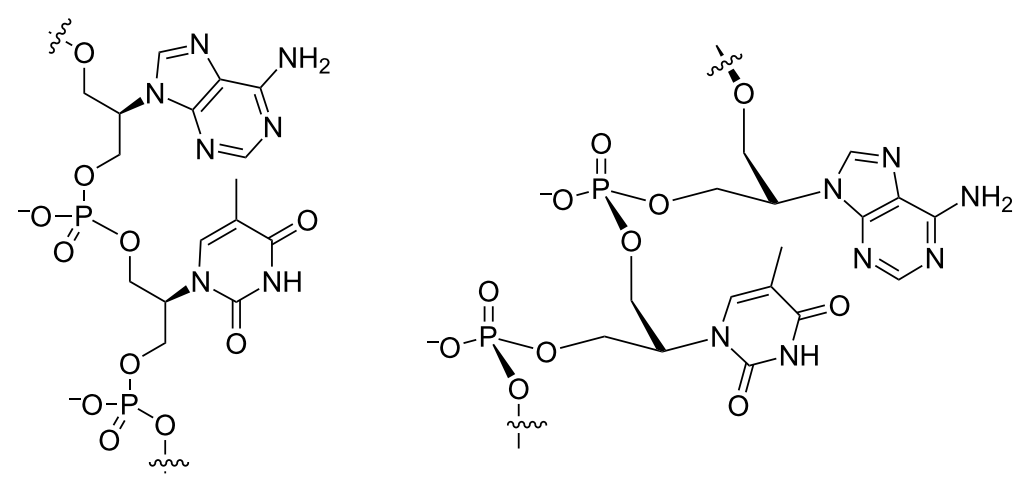

Figure 1: A constitutional and conformational (idealized) representation of isoGNA, an isomer of glycerol nucleic acid.

the nature of the nucleobase. Herein, we detail our synthetic efforts and the current improvements for the synthesis of all four isoGNA nucleosides and their phosphoramidites.

\section{Results and Discussion Initial synthetic routes}

We started with commercially available $(S)$-solketal (1), which was protected as the benzyl ether $\mathbf{2}$. Ketal deprotection followed by the silylation of the primary hydroxy group with tertbutyldiphenylsilyl chloride provided the substrate 4 , which is suitable for the introduction of the canonical nucleobases by a $\mathrm{S}_{\mathrm{N}} 2$ displacement reaction. At this point, we chose the Mitsunobu reaction (Scheme 1), which has been widely employed [16]. The reaction with the $N^{3}$-benzoyl protected thymine delivered $\mathbf{5}$ in good yield. However, the reaction with $N^{6}$-benzoyladenine proved problematic and no product was detected. Therefore, in the adenine case, we tried a direct $\mathrm{S}_{\mathrm{N}} 2$ reaction of $N^{6}$-benzoyladenine with tosyl derivative $\mathbf{6}$, which was only moderately successful (30\% yield of 7$)$. Unexpectedly, in both the thymine and adenine cases, the subsequent debenzylation reaction failed under a variety of conditions $\left(\mathrm{H}_{2}\right.$, $10 \% \mathrm{Pd} / \mathrm{C}, \mathrm{MeOH}$ or EtOAc; $\mathrm{Pd} / \mathrm{C}$, DMF, cyclohexadiene; $10 \%$ $\mathrm{Pd} / \mathrm{C}, \mathrm{NH}_{4} \mathrm{HCOO}$, acetone, reflux; $10 \%$ Pd-black, DMF, cyclohexadiene; $\left.\left(\mathrm{CH}_{3}\right)_{3} \mathrm{SiI}, \mathrm{CHCl}_{3}, 25^{\circ} \mathrm{C}\right)$, for reasons that were not obvious to us. Consequently, we abandoned this approach and pursued a different protecting group approach.

We silylated 1 to afford 8 whose ketal was deprotected followed by tritylation to give the derivative $\mathbf{1 0}$, which is expected to be suited for the introduction of nucleobases by an $\mathrm{S}_{\mathrm{N}} 2$ reaction (Scheme 2). Once again, the Mitsunobu reaction with thymine proceeded smoothly. However, the reaction with

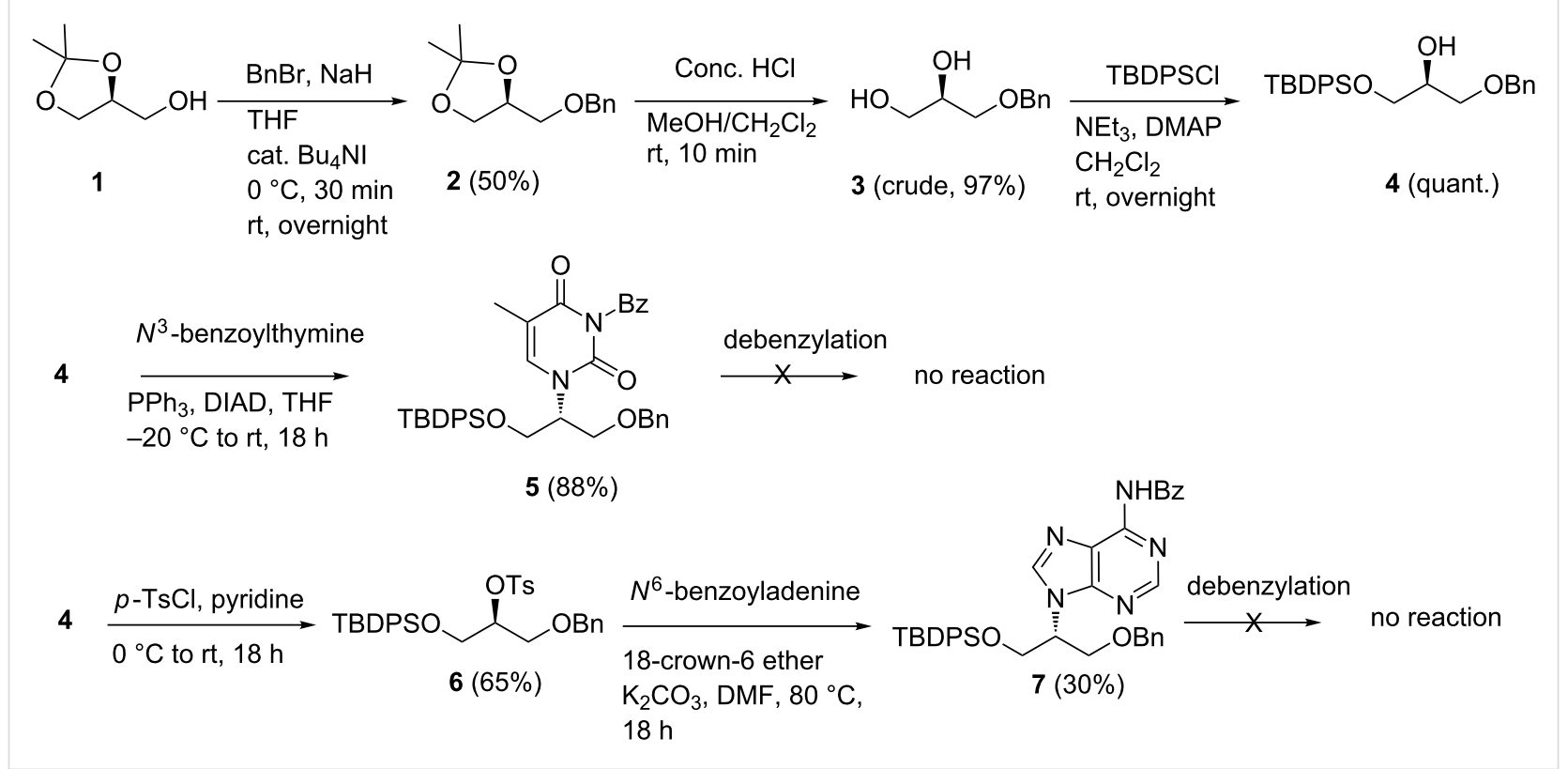



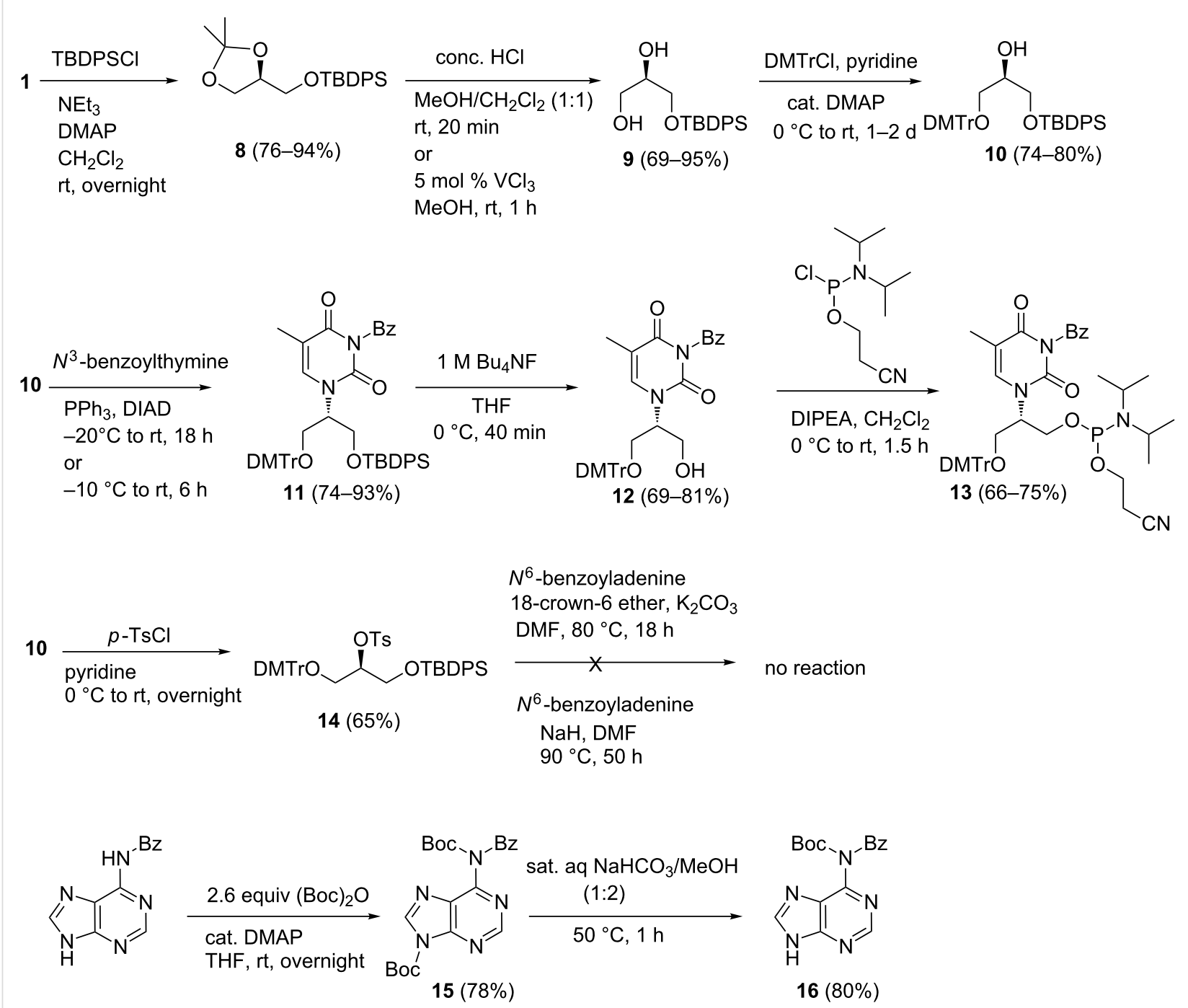<smiles>CC(C)(C)OC(=O)N(c1ccccc1)c1ncnc2[nH]cnc12</smiles>

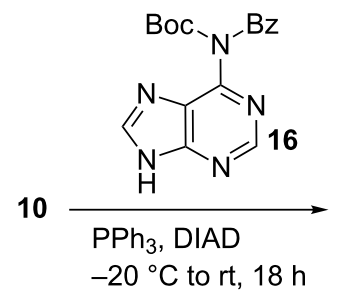

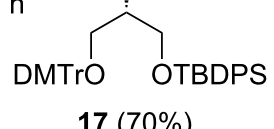

$17(70 \%)$<smiles>CC(C)n1cnc2c(N(C(=O)OC(C)(C)C)C(=O)c3ccccc3)ncnc21</smiles><smiles>CC(C)(C)OC(=O)c1ccccc1</smiles>

$18(68 \%)$

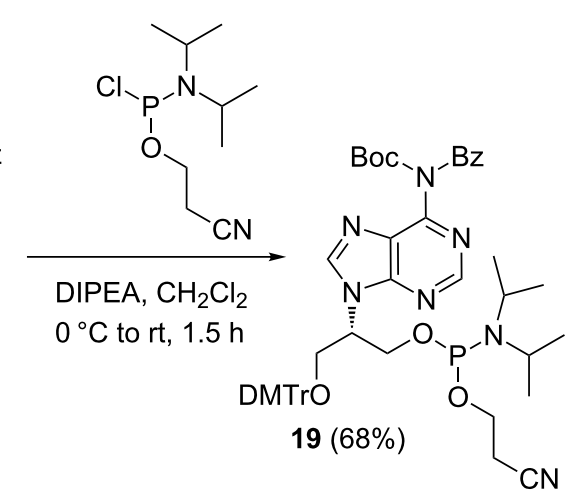

Scheme 2: Preparation of thymine and adenine containing phosphoramidites of isoGNA.

$N^{6}$-benzoyladenine proved problematic and did not proceed even with the tosyl derivative 14. The solubility issues with benzoylated adenine and the bulk of the O-TBDPS group may be the underlying reasons behind this difficulty. Therefore, we proposed to use a doubly $N^{6}$-protected adenine, the $N^{6}$-benzoyl-
Boc derivative 16, which was synthesized starting from $N^{6}$-benzoyladenine in two steps. $N^{6}$-Benzoyladenine was treated with 2.6 equiv (Boc) ${ }_{2} \mathrm{O}$ to afford $N^{6}$-benzoyl- $N^{6}, N^{9}$-diBoc-adenine 15; sat. aq $\mathrm{NaHCO}_{3} / \mathrm{MeOH}(1: 2)$ conditions cleaved the $N^{9}$-Boc group of $\mathbf{1 5}$ specifically [17,18] to yield $\mathbf{1 6}$. 
The use of $\mathbf{1 6}$ in the subsequent Mitsunobu reaction afforded $68 \%$ of the desired product 17 . With derivatives 11 and 17 in hand we proceeded to prepare the corresponding phosphoramidite derivatives 13 and 19, respectively, under standard conditions as outlined in Scheme 2.

We proceeded to prepare the cytosine- and guanine-containing phosphoramidite by using the tritylated intermediate $\mathbf{1 0}$ as the starting point (Scheme 3). In the cytosine series we found that the normal $N^{4}$-benzoyl or $N^{4}$-acetyl protected cytosine did not give satisfactory yields under the Mitsunobu conditions. The best yields were achieved with $N^{4}$-isobutyrylcytosine as the nucleophile [19-21]. In the guanine series, the $N^{2}$-isobutyryl, $O^{6}$-diphenylcarbamoyl protected guanine worked well (Scheme 3) [22].
With all the four phosphoramidites in hand we proceeded to the automated synthesis of the oligomers, which proceeded smoothly with $\geq 95 \%$ coupling efficiency as determined by trityl assays. It was at the stage of the removal of the protecting groups to afford the free oligos that we encountered a severe problem with the adenine derivative. While the aqueous ammonia/methylamine base deprotection removed all base labile protecting groups (acetate, isobutyrate, diphenylcarbamoyl groups), the $N^{6}$-Boc protecting group on adenine was impervious. We tried different acidic conditions (trifluoroacetic acid, acetic acid with heat, $\mathrm{AlCl}_{3}$ [23-25]), but all of these conditions started to degrade the oligomer without completely removing the tert-Boc group (as seen by MALDI-TOF mass spectral data in combination with ion-exchange HPLC monitoring) [8].<smiles>CC(C)C(=O)Nc1cc[nH]c(=O)n1</smiles><smiles>CC(C)C(=O)Nc1ccn(C(CO[18O])CO[18O])c(=O)n1</smiles><smiles>CC(C)C(=O)Nc1nc(OC(=O)C(C)C)c2nc[nH]c2n1</smiles>
dioxane, $65-70^{\circ} \mathrm{C}, 6 \mathrm{~h}$

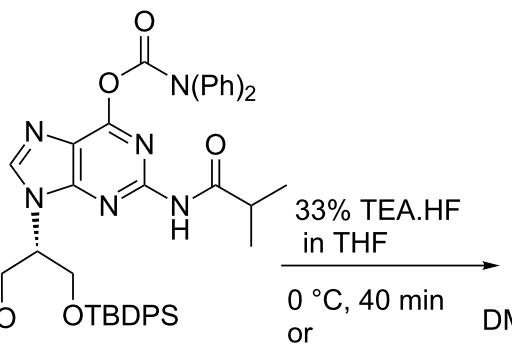
rt, $22 \mathrm{~h}$

$23(47-58 \%)$

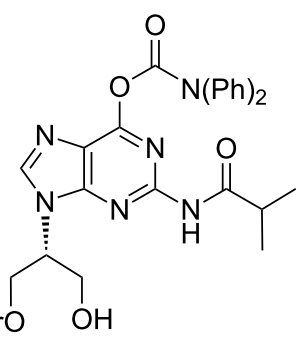

$24(73-81 \%)$

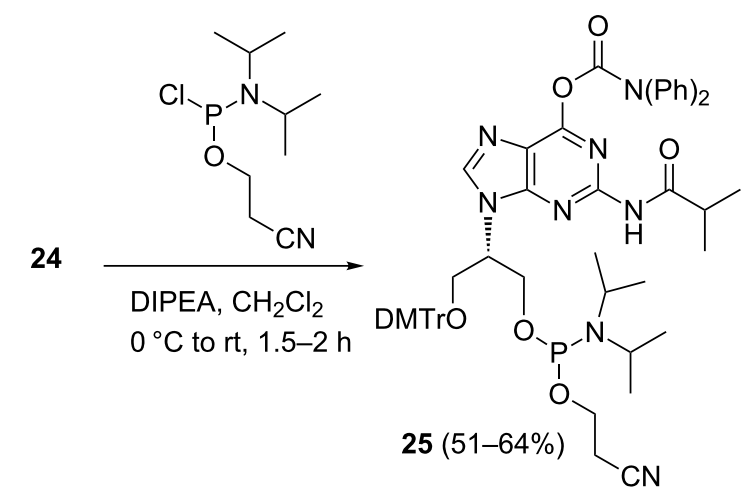




\section{Improved synthesis of adenine-isoGNA building block}

We went back in our synthesis in order to address the adenine protecting group problem and to re-work the inefficient Mitsunobu reaction of $N^{6}$-benzoyladenine. We explored various conditions (different solvents, temperature etc.) and found that the sonication [26] of the reaction mixture by using $N^{6}$-benzoyladenine in anhydrous dioxane led to respectable yields (34-36\%) of 26 accompanied by a (unidentified) byproduct (Scheme 4). Without sonication no product $\mathbf{2 6}$ was formed (by TLC).

However, the yield of the sonication reaction varied capriciously and the isolation of the compound was complicated by interference from the DEAD side-products during column chromatographic purification. We did manage to get enough amounts of $\mathbf{2 6}$ to prepare the phosphoramidite $\mathbf{2 8}$, and proceeded with the oligomer synthesis for our studies. However, this was far from satisfactory, and the continued demand for isoGNA oligomers within our group and our collaborative work prompted us to look for an improvement of the preparation of the adenine building block. Considering the possible reasons for the inefficient reaction of the protected adenine derivatives in the Mitsunobu reaction, we focused on the modification of adenine in order to improve its solubility.

We considered three different derivatives of adenine based on increased solubility: 6-chloroadenine has been utilized to overcome the solubility and regioselectivity $\left(N^{7}\right.$ versus $N^{9}$ nucleosidation) issues. Yet, the conversion of the chloro to the $\mathrm{NH}_{2}$ group is not efficient enough to consider this option an attractive one [27]. The second option was the $N^{6}, N^{6}$-dibenzoyladenine derivative, but this compound was found to be highly unstable for isolation and handling (one of the $N^{6}$-benzoyl group falls off very easily). The third option was the use of the $N^{6}, N^{6}$-di-Boc-adenine derivative, even though this entails the difficulty in removing these Boc groups, which are incompatible with the oligonucleotide backbone. Therefore, we consid- ered the option of removing these Boc groups after the Mitsunobu reaction is performed, and to introduce the $N^{6}$-benzoyl group before the oligo stage.

The Schneller group has reported that $N^{6}$-amino-di-Bocprotected adenine undergoes an efficient reaction under classic Mitsunobu conditions as a result of its increased solubility [28]. The regioselective attack at the $N^{9}$-position is a consequence of the steric bulk of the di-Boc protection at the $N^{6}$-position, which renders the $N^{7}$-position inaccessible. As expected, a high yield was observed under mild conditions with substrates containing a secondary alcohol [28].

Di-Boc protected adenine was readily prepared via protection and followed by selective deprotection according to a literature procedure [17,18]. The Mitsunobu reaction between the di-Bocadenine and $\mathbf{1 0}$ was investigated, and it was found that dioxane as a solvent almost doubled the yield (74\%) compared to THF (36\%; Scheme 5). Interestingly, sonication afforded no tangible advantage. Doubling the amount of DIAD or di-Boc-adenine or $\mathrm{PPh}_{3}$ did not give increased yields. The desired product 29 was easily purified on silica gel due to its lower polarity (when compared with the $N^{6}$-benzoyladenine reaction).

Initially, we tried to simultaneously deprotect both Boc groups and the TBDPS group in the presence of TBAF in a one-pot

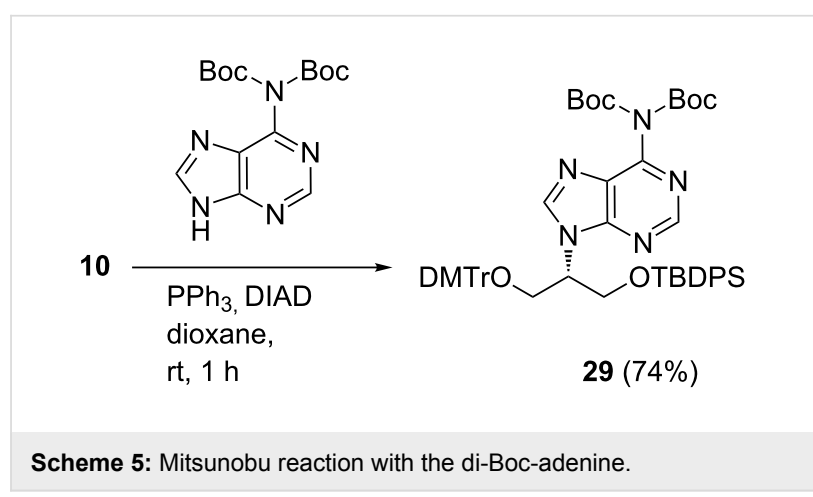

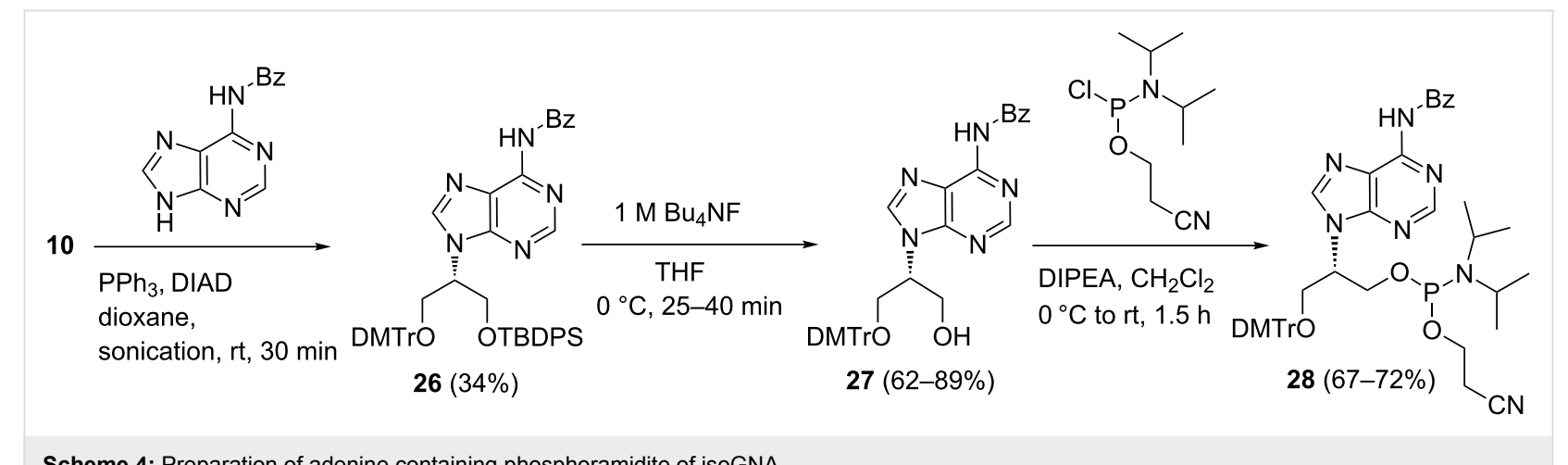


reaction [29]. However, only the TBDPS group was removed and a quantitative amount of mono-protected compound $\mathbf{3 0}$ was produced (Scheme 6). The fluoride ion was not effective enough to remove at least one of the Boc groups in 29. We checked the deprotection conditions for the removal of the Boc moiety by fluoride ions on the model substrate $N^{6}, N^{6}$-di-Bocadenine, and found that it was very challenging because free adenine was not afforded even under reflux with $1 \mathrm{M}$ TBAF for 4 days.

Finally, we decided to remove the Boc groups on adenine with trifluoroacetic acid (TFA), even though we also expected the loss of the DMTr group on $\mathbf{2 9}$. When $\mathbf{2 9}$ was treated with $20 \%$ of TFA in $\mathrm{CH}_{2} \mathrm{Cl}_{2}$, a mixture of $\mathbf{3 2}$ and $\mathbf{3 3}$ formed after $4 \mathrm{~h}$. The TBDPS moiety was found to be stable under these conditions (Table 1, entry 1 ). $50 \%$ of TFA in $\mathrm{CH}_{2} \mathrm{Cl}_{2}$ completely removed both Boc groups on adenine at either $4{ }^{\circ} \mathrm{C}$ or $\mathrm{rt}$ to afford the desired $\mathbf{3 3}$ in $87 \%$ yield.
The trityl group was reintroduced on $\mathbf{3 3}$ under standard conditions to give 34, and subsequent benzoylation afforded 26 in overall good yields (Scheme 7). The NMR spectra of $\mathbf{2 6}$ were in good agreement with those data obtained previously [8] via Mitsunobu reaction with $N^{6}$-benzoyladenine.

Overall, 26 was afforded in $43 \%$ yield from the Mitsunobu reaction of $\mathbf{1 0}$ with $N^{6}, N^{6}$-di-Boc-adenine. In addition to the slight improvement compared to the direct Mitsunobu reaction of 10 with $N^{6}$-benzoyladenine, this protocol allows for the synthesis of large amounts of $\mathbf{2 6}$ with an exact control of the regioselectivity at the $N^{9}$-position of adenine.

Having solved the "adenine problem", we focused on each of the remaining steps and optimized the synthesis of other isoGNA phosphoramidites. For example, the deprotection of $\mathbf{8}$ to 9 was initially achieved by the treatment with conc. $\mathrm{HCl}$. However, in scaling up the reaction, the loss of the silyl group

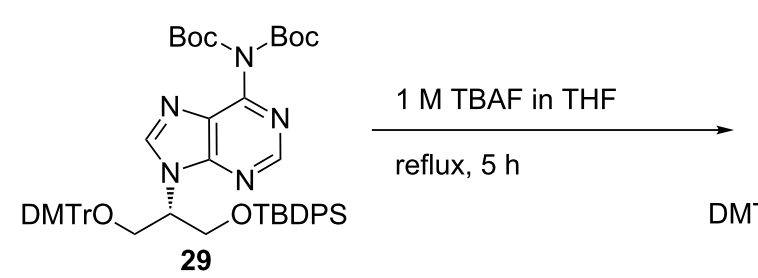

29

DMTrO<smiles>CCC(CO)n1cnc2c(N(C(=O)OC(C)(C)C)C(=O)OC(C)(C)C)ncnc21</smiles><smiles>CC(C)(C)OC(=O)N(C(=O)OC(C)(C)C)c1ncnc2[nH]cnc12</smiles><smiles>Nc1ncnc2[nH]cnc12</smiles>

Scheme 6: An attempt to remove both Boc and silyl groups simultaneously.

Table 1: Result of Boc deprotection of 29 with TFA.

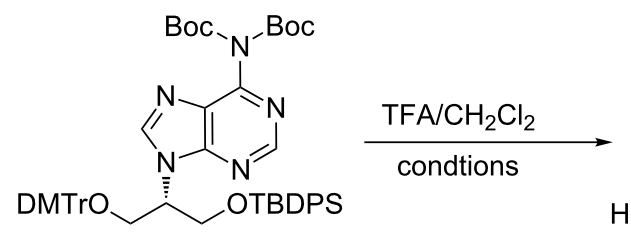

29<smiles>CC(C)(C)OC(=O)N(C(=O)OC(C)(C)C)c1ncnc2c1ncn2C(CO)CO</smiles>

31<smiles>CC(C)(C)O[13C](=O)c1ncnc2c1ncn2C(CO)CO</smiles>

32

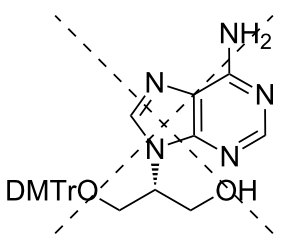

\begin{tabular}{|c|c|c|c|c|c|}
\hline Entry & Ratio of TFA (\%) & Temp. $^{a}$ & Time (h) & $\begin{array}{l}\text { Ratio }(\%)^{b} \\
(31: 32: 33)\end{array}$ & Yield \\
\hline 1 & 20 & $0^{\circ} \mathrm{C}$ to $\mathrm{rt}$ & 4 & $0: 33: 66$ & - \\
\hline \multirow[t]{2}{*}{2} & 50 & $0^{\circ} \mathrm{C}$ to $4{ }^{\circ} \mathrm{C}$ & 2 & $0: 20: 80$ & - \\
\hline & & & 4 & $0: 0: 100$ & - \\
\hline $3^{c}$ & 50 & $0^{\circ} \mathrm{C}$ to $\mathrm{rt}$ & 2 & $0: 0: 100$ & $87 \%$ \\
\hline
\end{tabular}

aTFA (99\%) was added under ice-bath $\left(-2\right.$ to $\left.2^{\circ} \mathrm{C}\right)$ cooling. ${ }^{\mathrm{b}}$ The ratio is roughly calculated by the intensity of visualized spots on TLC by UV lamp. ${ }^{\mathrm{C}} \mathrm{This}$ reaction was performed on a large scale. 


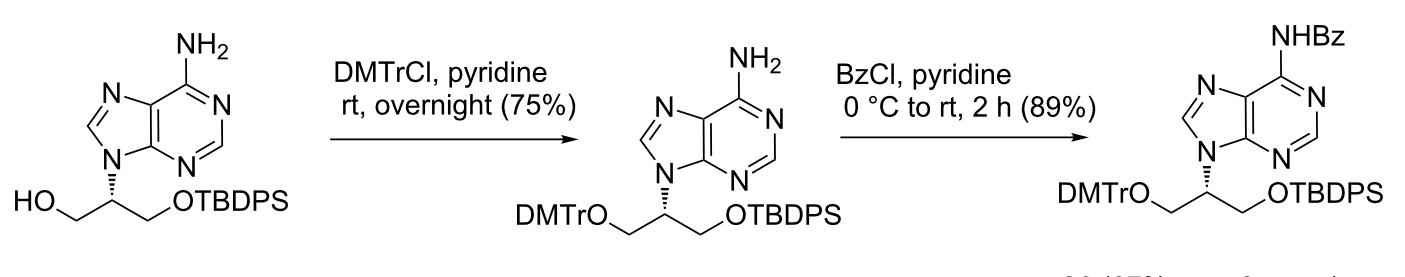

$26(67 \%$ over 2 steps $)$

Scheme 7: The synthesis of $\mathbf{2 6}$ via tritylation and benzoylation.

was found to occur. Therefore, we sought an alternative route and found that the deprotection mediated by vanadium trichloride gave the desired product 9 cleanly in large-scale reactions [30]. The desilylation of intermediates $\mathbf{1 1}, \mathbf{2 0}$ and $\mathbf{2 6}$ was effected by the treatment of $1 \mathrm{M} \mathrm{TBAF}$ in THF at $0{ }^{\circ} \mathrm{C}$ to room temperature. In the case of guanine derivative $\mathbf{2 3}$, we observed that the use of the triethylamine $\cdot \mathrm{HF}$ complex instead of TBAF was preferable at room temperature. The free alcohols 12, 18, $\mathbf{2 1}$ and $\mathbf{2 4}$ were phosphitylated under standard conditions to obtain the phosphoramidites suitable for the automated solid phase synthesis.

\section{Conclusion}

We have described herein improvements to and the optimization of the synthesis of isoGNA phosphoramidite building blocks. We observed that the Boc protecting group on adenine while not being compatible with oligonucleotide chemistry, can nevertheless be used as a temporary protecting group, which is extremely useful for increasing the solubility and regioselectivity of adenine in the Mitsunobu reaction. The optimized procedures described here allowed us to access a stable supply of isoGNA phosphoramidites for further investigation in our laboratory.

\section{Supporting Information}

\section{Supporting Information File 1}

Experimental procedures.

[http://www.beilstein-journals.org/bjoc/content/

supplementary/1860-5397-10-220-S1.pdf]

\section{Supporting Information File 2}

\section{${ }^{1} \mathrm{H},{ }^{13} \mathrm{C}$ and ${ }^{31} \mathrm{P}$ NMR spectra.}

[http://www.beilstein-journals.org/bjoc/content/ supplementary/1860-5397-10-220-S2.pdf]

\section{Acknowledgements}

This work was jointly supported by the NSF and NASA Astrobiology Program under the NSF Center for Chemical Evolution,
Grant CHE-1004570 and by NASA Astrobiology: Exobiology and Evolutionary Biology Program (Grant NNX09AM96G).

\section{References}

1. Vandendriessche, F.; Augustyns, K.; Van Aerschot, A.; Busson, R.; Hoogmartens, J.; Herdewijn, P. Tetrahedron 1993, 49, 7223-7238. doi:10.1016/S0040-4020(01)87200-8

2. Nielsen, P.; Dreiøe, L. H.; Wengel, J. Bioorg. Med. Chem. 1995, 3 , 19-28. doi:10.1016/0968-0896(94)00143-Q

3. Zhang, S.; Switzer, C.; Chaput, J. C. Chem. Biodiversity 2010, 7, 245-258. doi:10.1002/cbdv.200900281

4. Kumar, V.; Gore, K. R.; Pradeepkumar, P. I.; Kesavan, V. Org. Biomol. Chem. 2013, 11, 5853-5865. doi:10.1039/c3ob41244j

5. Murayama, K.; Tanaka, Y.; Toda, T.; Kashida, H.; Asanuma, H. Chem. - Eur. J. 2013, 19, 14151-14158. doi:10.1002/chem.201301578

6. Perlíková, P.; Karlsen, K. K.; Pedersen, E. B.; Wengel, J. ChemBioChem 2014, 15, 146-156. doi:10.1002/cbic.201300567

7. Li, P.; Sun, J.; Su, M.; Yang, X.; Tang, X. Org. Biomol. Chem. 2014, 12, 2263-2272. doi:10.1039/c3ob42291g

8. Karri, P.; Punna, V.; Kim, K.; Krishnamurthy, R. Angew. Chem., Int. Ed. 2013, 52, 5840-5844. doi:10.1002/anie.201300795

9. Krishnamurthy, R. Synlett 2014, 25, 1511-1517. doi:10.1055/s-0033-1340183

10. Mikhailov, S. N.; Smrt, J. Collect. Czech. Chem. Commun. 1975, 40, 3080-3085. doi:10.1135/cccc19753080

11. Hiller, S. A.; Zarin, D. E.; Zhuk, R. A. Nucleic Acids Res. 1976, 3 , 721-728. doi:10.1093/nar/3.3.721

12. Capaldi, D. C.; Eleuteri, A.; Chen, Q.; Schinazi, R. F. Nucleosides Nucleotides 1997, 16, 403-416. doi:10.1080/07328319708001358

13. Cadet, G.; Chan, C.-S.; Daniel, R. Y.; Davis, C. P.; Guiadeen, D.; Rodriguez, G.; Thomas, T.; Walcott, S.; Scheiner, P. J. Org. Chem. 1998, 63, 4574-4580. doi:10.1021/jo9715231

14. Rosenberg, I.; Holý, A.; Masojídoková, M. Collect. Czech. Chem. Commun. 1988, 53, 2753-2777. doi:10.1135/cccc19882753

15. Vrbovská, S.; Holý, A.; Pohl, R.; Masojídoková, M. Collect. Czech. Chem. Commun. 2006, 71, 543-566. doi:10.1135/cccc20060543

16. Lowe, G.; Vilaivan, T. J. Chem. Soc., Perkin Trans. 1 1997, 539-546. doi:10.1039/a603696a

17. Dey, S.; Garner, P. J. Org. Chem. 2000, 65, 7697-7699. doi:10.1021/jo000983i

18. Porcheddu, A.; Giacomelli, G.; Píredda, I.; Carta, M.; Nieddu, G. Eur. J. Org. Chem. 2008, 5786-5797. doi:10.1002/ejoc.200800891 
19. Antle, V. D.; Caperelli, C. A. Nucleosides Nucleotides 1999, 18, 1911-1928. doi:10.1080/07328319908044853

20. Choo, H.; Chong, Y.; Chu, C. K. Org. Lett. 2001, 3, 1471-1473. doi:10.1021/ol015783n

21. Shatila, R. S.; Bouhadir, K. H. Tetrahedron Lett. 2006, 47, 1767-1770. doi:10.1016/j.tetlet.2006.01.035

22. Lu, W.; Sengupta, S.; Petersen, J. L.; Akhmedov, N. G.; Shi, X. J. Org. Chem. 2007, 72, 5012-5015. doi:10.1021/jo070515+

23. James, K. D.; Ellington, A. D. Tetrahedron Lett. 1998, 39, 175-178. doi:10.1016/S0040-4039(97)10509-3

24. James, K. D.; von Kiedrowski, G.; Ellington, A. D. Nucleosides Nucleotides 1997, 16, 1821-1836. doi:10.1080/07328319708002536

25. Pothukanuri, S.; Pianowski, Z.; Winssinger, N. Eur. J. Org. Chem. 2008, 3141-3148. doi:10.1002/ejoc.200800141

26. Lepore, S. D.; He, Y. J. Org. Chem. 2003, 68, 8261-8263. doi:10.1021/jo0345751

27. Perez-Perez, M.-J.; Rozenski, J.; Busson, R.; Herdewijn, P. J. Org. Chem. 1995, 60, 1531-1537. doi:10.1021/jo00111a010

28. Yin, X.-q.; Li, W.-k.; Schneller, S. W. Tetrahedron Lett. 2006, 47, 9187-9189. doi:10.1016/j.tetlet.2006.10.126

29. Jacquemard, U.; Bénéteau, V.; Lefoix, M.; Routier, S.; Mérour, J.-Y.; Coudert, G. Tetrahedron 2004, 60, 10039-10047. doi:10.1016/j.tet.2004.07.071

30. Sabitha, G.; Reddy, G. S. K. K.; Reddy, K. B.; Reddy, N. M.; Yadav, J. S. J. Mol. Catal. A: Chem. 2005, 238, 229-232. doi:10.1016/j.molcata.2005.05.028

\section{License and Terms}

This is an Open Access article under the terms of the Creative Commons Attribution License (http://creativecommons.org/licenses/by/2.0), which permits unrestricted use, distribution, and reproduction in any medium, provided the original work is properly cited.

The license is subject to the Beilstein Journal of Organic Chemistry terms and conditions:

(http://www.beilstein-journals.org/bjoc)

The definitive version of this article is the electronic one which can be found at: $\underline{\text { doi: } 10.3762 / \text { bjoc. } 10.220}$ 